\title{
Investigação de cafeína, Genfibrozila, Bezafibrato, Metformina, Prometazina e Loratadina em águas de sistema de abastecimento público
}

\author{
Investigation of caffeine, Gemfibrozil, Bezafibrate, Metformine, Prometazine, \\ and Loratadine in waters of public supply systems \\ Juliane Ribeiro das Chaves ${ }^{1 *} \oplus$, Luiza Carla Girard Mendes Teixeira' ${ }^{1}$, \\ Neyson Martins Mendonça' ${ }^{\oplus}$, Sérgio Francisco de Aquino ${ }^{2} \odot$
}

\begin{abstract}
RESUMO
O presente estudo teve por objetivo investigar a presença dos fármacos Cafeína, Genfibrozila, Bezafibrato, Metformina, Prometazina e Loratadina em manancial superficial e em água para consumo. Para determinar a ocorrência desses fármacos, foram realizadas seis campanhas amostrais durante o período chuvoso e seis durante o período seco, em três pontos de coleta localizados no Complexo Bolonha, cidade de Belém, região Norte do Brasil: reservatório Bolonha (captação) e estação de tratamento de água Bolonha (câmara de água filtrada e reservatório de água tratada). Para a avaliação das remoções dos fármacos nas etapas de filtração e desinfecção (com gás cloro) foram calculadas as eficiências de cada um desses processos e foi avaliada a remoção ao fim do tratamento. Como esperado, a água bruta apresentou maiores concentrações de fármacos do que a água tratada. As concentrações dos reguladores lipídicos Bezafibrato e Genfibrozila variaram de 11,4 a 1364,9 ng. L'-1 na água bruta e de 15,7 a 435,9 ng. L' na água tratada. Já o antialérgico Loratadina foi o fármaco com maior frequência de ocorrência, e sua concentração variou de 15,7 a 45,0 ng. L-1 na água bruta e de 15,2 a 24,3 ng. $\mathrm{L}^{-1}$ na água tratada. Os resultados indicam a influência antrópica que o reservatório e a estação de tratamento de água vêm sofrendo e mostram que o tratamento de ciclo completo utilizado na estação de tratamento de água Bolonha não foi eficiente para a remoção completa dos compostos de preocupação emergente investigados. As remoções médias anuais foram de 5\% para Genfibrozila, 26\% para Loratadina e 52\% para Bezafibrato, sendo a cloração particularmente importante para a remoção de Genfibrozila e Cafeína.
\end{abstract}

Palavras-chave: fármacos; microcontaminantes; influência antrópica; água potável.

\begin{abstract}
The present study aimed to investigate the occurrence of the drugs Caffeine, Gemfibrozil, Bezafibrate, Metformin, Promethazine, and Loratadine in water supply and water for human consumption. To determine the occurrence of drugs, six sampling campaigns were carried out during the rainy season and six during the dry season, at three collection points located in the Bolonha Complex, Belém city, Northern Brazil: Bolonha reservoir (catchment) and Bolonha filtered water chamber and treated water reservoir. To evaluate the removal of drugs in the filtration and disinfection stages, the efficiencies of each of these processes were calculated, in addition to the removal evaluation at the end of the treatment. The raw water was the one with the highest concentrations of drugs, while the treated water had lower concentrations. The concentrations of lipid regulators Bezafibrate and Gemfibrozil ranged from 11.4 to $1,364.9$ ng.' in raw water and from 15.7 to $435.9 \mathrm{ng} \cdot \mathrm{L}^{-1}$ in treated water. The antiallergic Loratadine was the drug with the highest frequency of occurrence whose concentration ranged from 15.7 to $45.0 \mathrm{ng} \cdot \mathrm{L}^{-1}$ in raw water and from 15.2 to

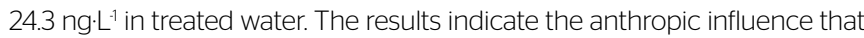
the reservoir and the filtered water chamber and treated water reservoir have been suffering and show that the full cycle treatment used in Bolonha filtered water chamber and treated water reservoir was not efficient for the complete removal of the compounds of emerging concern investigated. The average annual removals were, respectively, 5\% for Gemfibrozil, 26\% for Loratadine, and $52 \%$ for Bezafibrate. The chlorination step seemed to be particularly important for the removal of Gemfibrozil and Caffeine.
\end{abstract}

Keywords: drugs; microcontaminants; anthropic influence; drinking water.

Universidade Federal do Pará - Belém (PA), Brasil.

¿Universidade Federal de Ouro Preto - Ouro Preto (MG), Brasil.

*Autor correspondente: juliane.rib21@gmail.com

Conflitos de interesse: os autores declaram não haver conflitos de interesse.

Financiamento: este estudo recebeu financiamento da Fundação Nacional de Saúde (FUNASA) - TED 010/2014.

Recebido: 08/10/2020 - Aceito: 04/01/2021 - Reg. ABES: 20200352 


\section{INTRODUÇÃO}

A exposição humana a contaminantes que ocorrem na água em pequenas concentrações, na faixa de ng. $\mathrm{L}^{-1}$ a $\mu \mathrm{g} \cdot \mathrm{L}^{-1}$, e por isso denominados microcontaminantes, tem-se tornado uma questão de preocupação científica que pode vir a ser um problema de saúde pública, uma vez que são muitos os grupos de compostos naturais e sintéticos, entre os quais se destacam os fármacos, com variados graus de toxicidade. Eles podem chegar aos recursos hídricos e à água potável por diversas vias, como, por exemplo, efluentes, lixiviados de aterro e descarte inadequado de fármacos vencidos nos sanitários. Os medicamentos estão incluídos em várias classes farmacêuticas, que com os avanços tecnológicos e medicinais aumentaram significativamente em tipo e quantidade (BISOGNIN, WOLFF \& CARISSIMI, 2018; GARCÍA-GIL et al., 2018). Contudo, com os avanços de tecnologia, houve também a evolução de técnicas analíticas. Consequentemente, tornou-se possível a detecção e a quantificação de vários resíduos farmacêuticos não somente em efluentes, mas também em águas: superficiais, subterrâneas e potáveis (CASTIGLIONI et al., 2018; BRANCHET et al., 2019).

Técnicas de separação, como cromatografia de fases gasosa e líquida, e de detecção, como espectrometria de massas, possibilitaram a quantificação de contaminantes mesmo em baixas concentrações (OSAWA et al., 2015; LIMA et al., 2017). Perante isso, uma grande quantidade de compostos inalterados ou metabólitos tem sido detectada e quantificada com frequência em diversas matrizes ambientais (esgoto, águas superficiais, subterrâneas, tratadas e envasadas para consumo humano) em vários países. Dado o exposto, estudos têm sido realizados a fim de relatar possíveis efeitos dos medicamentos no ambiente e em seres humanos (MONTAGNER, VIDAL \& ACAYABA, 2017; BISOGNIN, WOLFF \& CARISSIMI, 2018), impactos que ainda não são totalmente compreendidos. Nesse sentido, o conhecimento sobre as concentrações dessas substâncias em matrizes aquáticas pode gerar subsídios para que elas se tornem candidatas a futura regulamentação (VERAS et al., 2019).

Pesquisas têm mostrado que tais medicamentos, mesmo em pequenas concentrações, podem causar efeitos adversos no ambiente receptor e permanecer na água tratada (GAFFNEY et al., 2014; MONTAGNER, VIDAL \& ACAYABA, 2017). O primeiro estudo publicado sobre a ocorrência de fármacos em águas é de 1976 (KEITH, 1976), entretanto, no Brasil, a primeira pesquisa realizada só foi publicada em 1999 (STUMPF et al., 1999). Consequentemente, em algumas regiões do país, como a Norte, há escassez de dados sobre a ocorrência desses contaminantes nas diversas matrizes ambientais, o que impede a adequada estimativa da sua concentração ambiental, uma vez que as características de poluição divergem de um lugar para outro. Sabe-se que a qualidade da água tratada é consequência tanto da condição do manancial de captação quanto da eficiência do tratamento (SIMAZAKI et al., 2015; MONTAGNER, VIDAL \& ACAYABA, 2017). Entretanto, sabe-se também que as estações de tratamento de esgoto e de água não foram projetadas com a finalidade de remover especificamente os diversos grupos de contaminantes de preocupação emergente (GAFFNEY et al., 2014; LIMA et al., 2017).

Em virtude do que foi mencionado, são necessárias pesquisas sobre esse assunto e sobre novas técnicas de remoção em tratamentos de esgoto e de água, e é particularmente importante o estudo da ocorrência desses compostos em sistemas de abastecimento de água tratada, a fim de contribuir e subsidiar ações governamentais. Dessa forma, a presente pesquisa teve por objetivo investigar a ocorrência de fármacos (estimulante Cafeína; reguladores lipídicos Bezafibrato e Genfibrozila; antidiabético Metformina; antialérgicos Prometazina e Loratadina) em água superficial e tratada no Complexo Bolonha. A área de estudo possui grande relevância, pois é responsável pelo abastecimento de aproximadamente $70 \%$ da população da Região Metropolitana de Belém (RMB) e está localizada no estado do Pará, na região Norte do Brasil. Assim, este trabalho poderá contribuir para o início de um banco de dados na região e para estudos futuros sobre a ocorrência de microcontaminantes nas águas do Norte do País.

\section{METODOLOGIA}

O Complexo Bolonha faz parte do sistema de abastecimento da RBM, onde estão inseridos os reservatórios Bolonha e Água Preta e a estação de tratamento de água (ETA) Bolonha, com localização nos limites da área de proteção ambiental de Belém (APA Belém), nas seguintes coordenadas: latitude 1² 25’ 14" S e longitude $48^{\circ} 26^{\prime} 04^{\prime \prime}$ O. Na APA Belém está inserido o Parque Estadual do Utinga (PEUt), que é uma Unidade de Conservação (UC) de proteção integral de 1.393 hectares (PARÁ, 2019), criada pelo Governo do Estado do Pará em 1993 (PARÁ, 1993) para assegurar a potabilidade da água dos mananciais por meio do manejo e da recuperação das áreas degradadas e para ampliar a vida útil dos reservatórios Bolonha $\left(2.000 .000 \mathrm{~m}^{3}\right)$ e Água Preta $\left(10.000 .000 \mathrm{~m}^{3}\right)$ (SEMA, 2013; BELÉM, 2015). Os reservatórios são reforçados pelo sistema adutor que transporta água do rio Guamá (BELÉM, 2015).

De acordo com Gutierrez et al. (2017) o PEUt é alvo de intensa influência antrópica em seu entorno. Há áreas consideradas desmatadas que foram invadidas para a construção de residências. Assim, o reservatório Bolonha, apesar de estar circunscrito em uma unidade de conservação, ao longo dos anos tem sofrido os impactos causados pela ocupação desordenada da população em seu entorno. Pode-se observar, pelo mapa de localização geográfica da área de estudo (Figura 1), a pressão urbana acentuada em torno do corpo hídrico, causada principalmente pelas invasões perto da cabeceira do manancial. Isso vem gerando lançamentos de esgotos sem tratamento e, consequentemente, crescimento excessivo de plantas aquáticas, que têm como fator substancial a maior concentração de nutrientes como nitrogênio e fósforo. Dessa forma, vem ocorrendo a aceleração do processo de eutrofização no reservatório, consequência da falta de planejamento de uso e ocupação do solo.

A água tratada na ETA Bolonha é de grande relevância para a população da cidade de Belém. Foi projetada com uma capacidade nominal de $6,4 \mathrm{~m}^{3} \cdot \mathrm{s}^{-1} \mathrm{e}$ é responsável pelo abastecimento da maior parte da RMB. É uma ETA de ciclo completo e foi implantada em duas etapas. A primeira ( $\left.1^{a}\right)$ foi inaugurada em 1986 e a segunda $\left(2^{\mathrm{a}}\right) \mathrm{em} 2010$, ambas com capacidade nominal de $3,2 \mathrm{~m}^{3} \cdot \mathrm{s}^{-1}$. Durante a pesquisa experimental, parte da $1^{\text {a }}$ etapa estava em reforma, fazendo com que ETA operasse com vazão de $5 \mathrm{~m}^{3} \cdot \mathrm{s}^{-1}$, inferior a $22 \%$ da capacidade total de projeto $\left(6,4 \mathrm{~m}^{3} \cdot \mathrm{s}^{-1}\right)$.

Para o planejamento das coletas, realizou-se análise com os dados de precipitação da estação pluviométrica mais próxima do Complexo Bolonha, na RMB. Na Figura 2, tem-se a normal pluviométrica no período de 1989 a 2018, junto do regime pluviométrico do ano de 2018, período no qual foram realizadas as coletas. De janeiro a março de 2018 foram coletadas as amostras do período chuvoso e, de setembro a novembro, as do período seco, somando ao todo 12 campanhas amostrais, o que totalizou, nos três pontos escolhidos (Figura 2), 36 amostras coletadas.

O primeiro ponto, chamado de água bruta $(\mathrm{AB})$, está localizado no reservatório Bolonha, na entrada da captação da estação elevatória de água bruta 


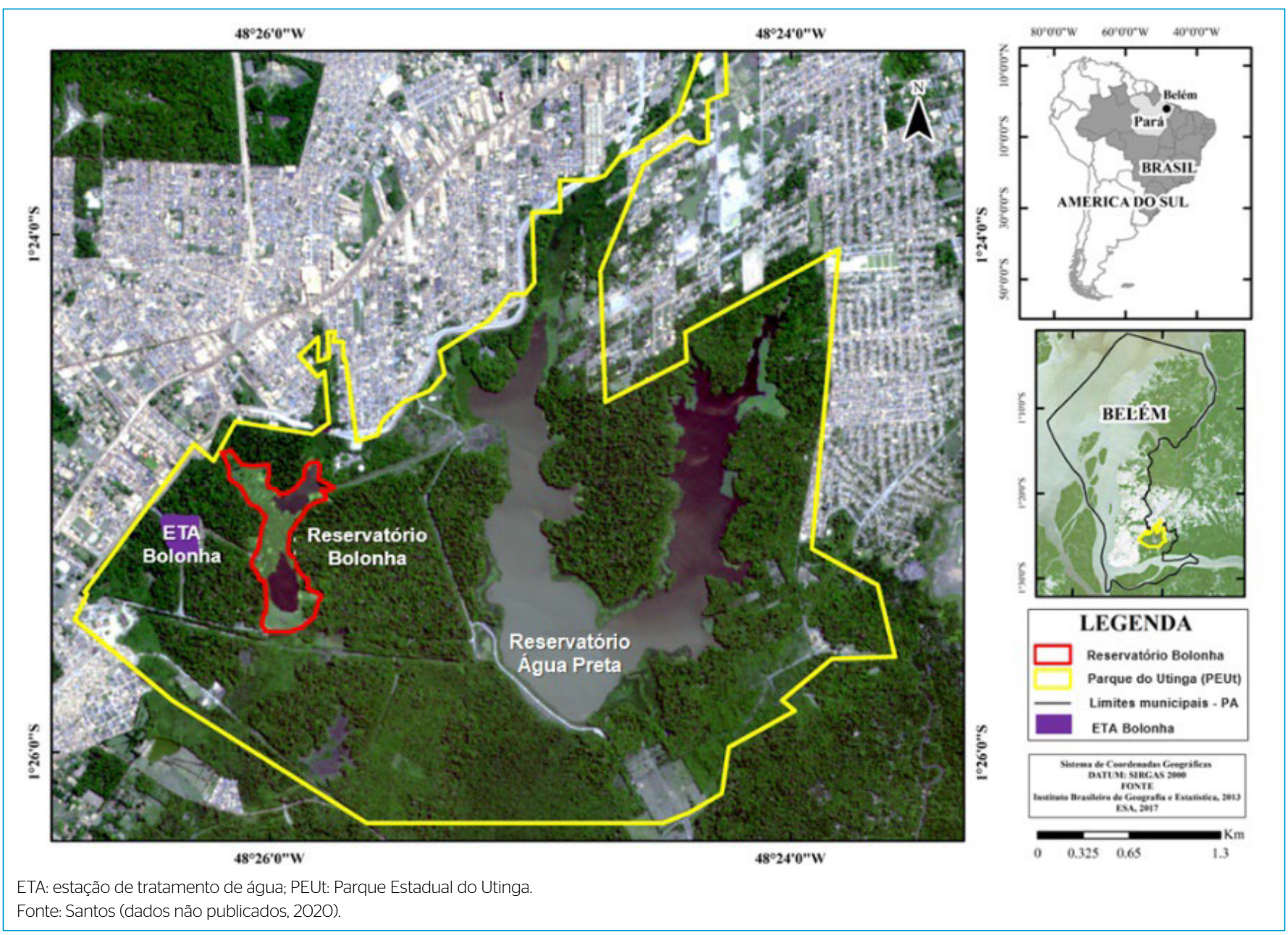

Figura 1 - Localização geográfica do Parque Estadual do Utinga, do reservatório Bolonha e da estação de tratamento de água Bolonha.

(EEAB) Bolonha. O segundo ponto, denominado água filtrada (AF), está situado na câmara de água filtrada da ETA Bolonha. Já o último e terceiro ponto, denominado água tratada (AT), está localizado na entrada do reservatório de água tratada da ETA em estudo. Assim, a escolha dos pontos teve por finalidade avaliar a contribuição das etapas de clarificação e de oxidação com cloro para a remoção dos microcontaminantes monitorados.

Para o cálculo das remoções de fármacos ao longo do tratamento de água, foram utilizadas as Equações 1, 2 e 3. Assim, a verificação da eficiência das etapas da ETA foi observada nas etapas de filtração e de desinfecção e ao término do tratamento.

Eficiência média de remoção Pós-Filt. $_{\text {. }}(\%)=\frac{\text { Média } A B-\text { MédiaAF }}{\text { Média } A B} \times 100$

Eficiência média de remoção $\mathrm{Pós}-$ Clor $_{\text {. }}(\%)=\frac{\text { MédiaAF }- \text { MédiaAT }}{\text { MédiaAF }} \times 100$

Eficiência média de remoção $\mathrm{T}_{\text {Total }}(\%)=\frac{\text { MédiaAB }- \text { MédiaAT }}{\text { MédiaAB }} \times 100$
A amostragem para determinação das variáveis investigadas foi do tipo composta. Foi utilizada a técnica de imersão do frasco numa profundidade de 0 a $30 \mathrm{~cm}$ da lâmina d’água (CETESB, 2011). Os procedimentos utilizados para a determinação das variáveis Cafeína, Genfibrozila, Bezafibrato, Metformina, Prometazina e Loratadina seguiram o método de extração em fase sólida (solid phase extraction - SPE) desenvolvido por Sanson (2012). Na Figura 3, apresentam-se as etapas do procedimento realizado em laboratório após cada campanha. A preparação de cada amostra dava-se pela filtração prévia para a remoção de sólidos suspensos, ajuste de $\mathrm{pH}$ para 2,00 $\pm 0,20$, adição de ácido etilenodiamino tetra-acético (EDTA) e extração nos cartuchos SPE.

O sistema de extração para SPE usado emprega um fluxo de nitrogênio gasoso $\left(\mathrm{N}_{2}(\mathrm{~g})\right)$ no interior do frasco âmbar que contém a amostra (Figura 4). A pressão positiva no frasco faz com que a amostra passe pela tubulação de aço-inox e, em seguida, pela fase estacionária do cartucho de extração com vazão constante, reduzindo assim o risco de contaminação e tornando o processo mais simples (SANSON et al., 2014). Assim, todo o processo de SPE foi composto de quatro fases: condicionamento, passagem das amostras pelos cartuchos SPE, secagem dos cartuchos e eluição que era realizada no dia da análise. Até a análise, os cartuchos SPE, que continham os fármacos de interesse 


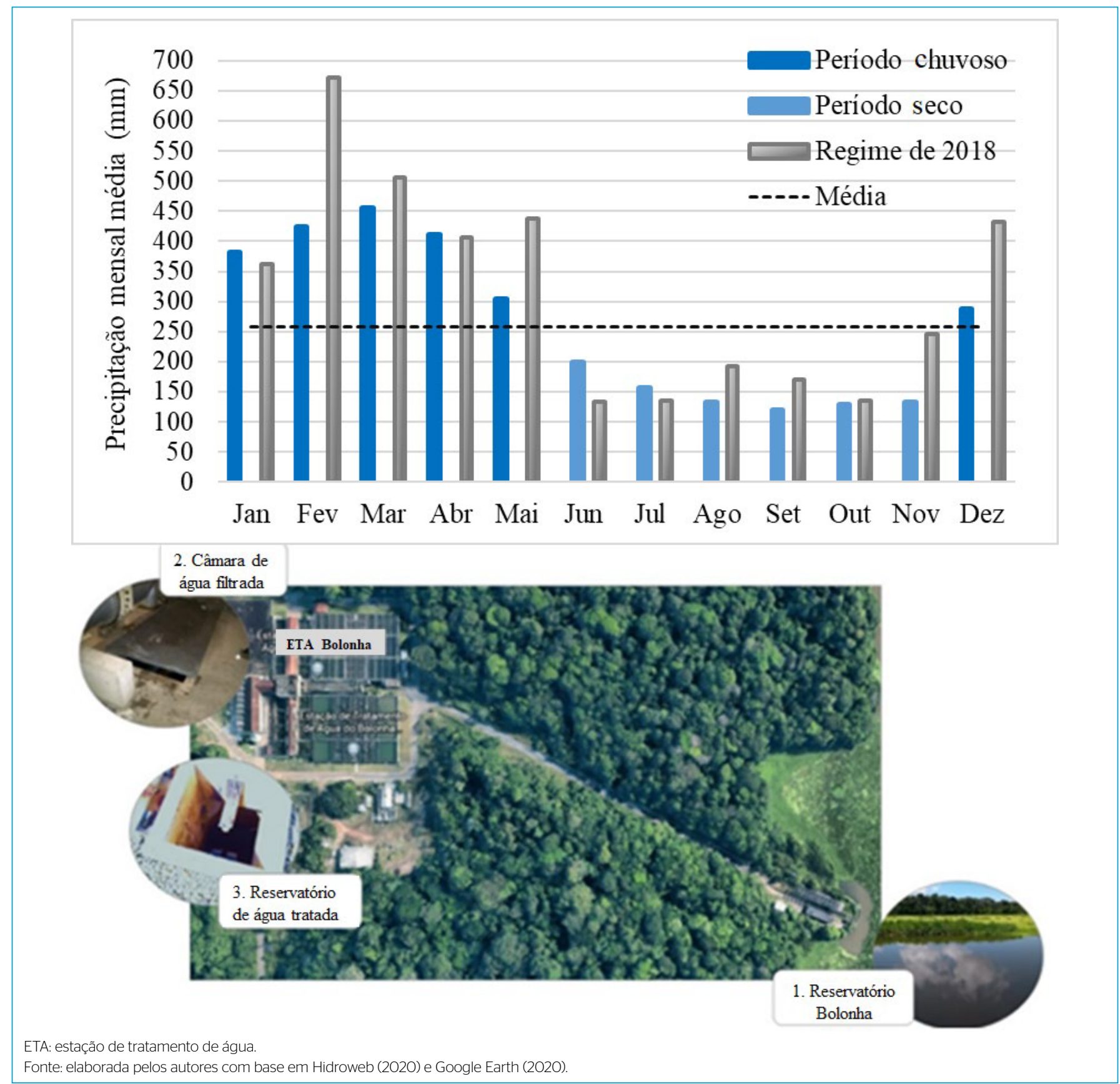

Figura 2 - Normal climatológica (1989-2018) e regime pluviométrico de 2018 em pontos de coleta no reservatório e na estação de tratamento de água de Bolonha.

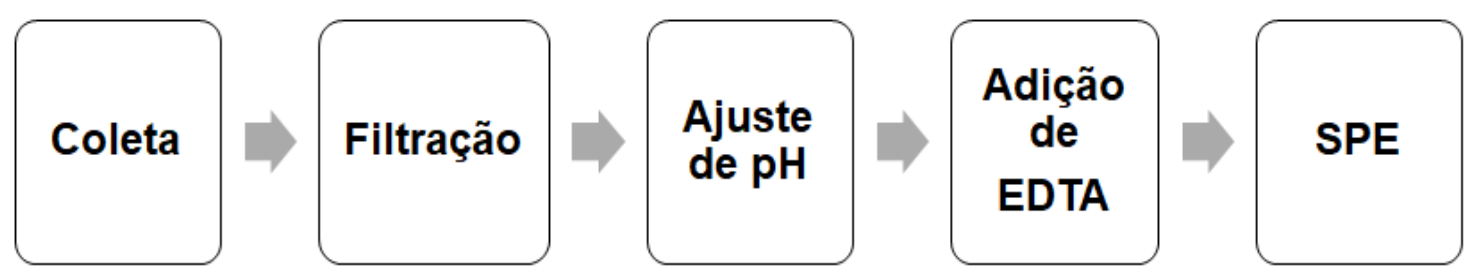

EDTA: ácido etilenodiamino tetra-acético; SPE: extração em fase sólida.

Fonte: elaborada pelos autores.

Figura 3 - Procedimento de preparação das amostras de fármacos. 


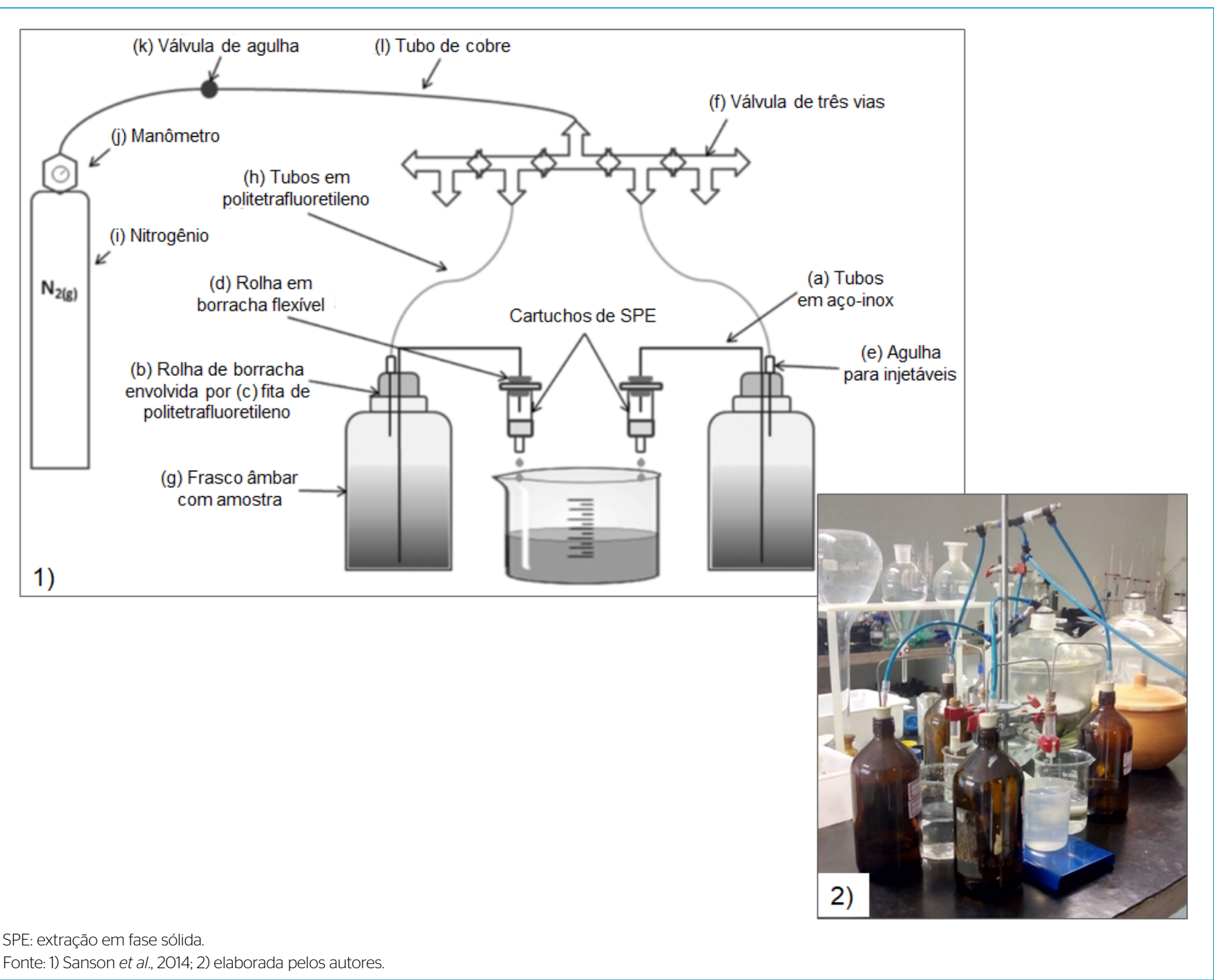

Figura 4 - Sistema de extração em fase sólida (aparato extrator) desenvolvido no Laboratório de Cromatografia e Espectrometria de Massas da Universidade Federal de Ouro Preto.

adsorvidos, eram envoltos em papel alumínio, colocados dentro de sacos plásticos e armazenados em freezer. A eluição dos fármacos adsorvidos no cartucho foi feita com 3 × $3 \mathrm{~mL}$ de acetato de etila, e o volume final foi aferido para $500 \mu \mathrm{L}$ para então se proceder à análise cromatográfica. O grupo de fármacos Cafeína, Metformina, Prometazina, Bezafibrato e Loratadina foi analisado por cromatografia líquida, e a Genfibrozila por cromatografia gasosa. Os limites de detecção e a quantificação de tais compostos estão apresentados na Tabela 1.

\section{RESULTADOS E DISCUSSÃO}

Diante dos limites de detecção e quantificação de cada método, apenas o antidiabético Metformina e o anti-histamínico Prometazina não foram detectados no sistema de abastecimento de água em estudo. Entre os fármacos estudados, o Bezafibrato foi quantificado em maiores concentrações (Tabela 2), que variaram entre 269,6 e 1364,9 ng. $\mathrm{L}^{-1}$, estando ele presente em 11\% das amostras analisadas. As maiores concentrações desse regulador lipídico em comparação aos outros compostos pode estar associada ao seu elevado consumo para a diminuição do colesterol lipoproteína de baixa densidade (LDL) e triglicerídeos no sangue, que são problemas recorrentes na população. Isso porque muitas vezes não se tem uma alimentação adequada; segundo o Ministério da Saúde, no ano de 2017, 18\% dos habitantes de Belém estavam obesos e 53,1\% tinham excesso de peso (MINISTÉRIO DA SAÚDE, 2018).

$\mathrm{Na} \mathrm{AB}$, o antilipêmico Bezafibrato ocorreu com concentrações mínima de 269,6 ng. $\mathrm{L}^{-1}$ e máxima de 1364,9 ng. $\mathrm{L}^{-1}$, com frequência de $17 \%$ de ocorrência nas amostras do reservatório Bolonha, e somente no período chuvoso (Figura 5). Em estudos realizados previamente em águas superficiais do Brasil e de outros países, as concentrações de Bezafibrato foram inferiores às obtidas neste estudo. $\mathrm{Na}$ bacia do Rio Doce, Rodrigues (2012) obteve concentrações que variaram de 50,1 a 1085,7 ng. $\mathrm{L}^{-1}$. Dias (2014), que investigou a ocorrência de Bezafibrato em alguns sistemas de abastecimento do país, relatou concentrações médias na AB que variaram de 124,21 ng. $\mathrm{L}^{-1}$ (Sistema Rio das Velhas/MG) a 206,20 ng. $\cdot \mathrm{L}^{-1}$ (Sistema Guandu/RJ). Estudos realizados na Sérvia, França, Alemanha e Espanha 
reportaram concentrações de Bezafibrato em águas naturais de, respectivamente, 1,6, 3,4, 16 e 350 ng.L-1 (MELO et al., 2009; VULLIET \& CREN-OLIVÉ, 2011; GROS, RODRÍGUEZ-MOZAZ \& BARCELÓ, 2012; PETROVIĆ et al., 2014).

O Bezafibrato não ocorreu na AF acima dos limites de detecção e esteve presente na AT somente no período seco (Figura 5), com variação de 347,6 ng. $\mathrm{L}^{-1}$

Tabela 1 - Limites de detecção e de quantificação do método analítico para os compostos analisados.

\begin{tabular}{l|c|c|c} 
Composto & Método de detecção & LD $\left(\mathbf{n g} \cdot \mathbf{L}^{-1}\right)$ & LQ $\left(\mathbf{n g} \cdot \mathbf{L}^{-1}\right)$ \\
\hline Cafeína & LC-MS/MS & 162,1 & 540,2 \\
\hline Genfibrozila & GC-MS & 0,3 & 1,1 \\
\hline Metformina & LC-MS/MS & 1,4 & 4,6 \\
\hline Prometazina & LC-MS/MS & 0,3 & 1,0 \\
\hline Bezafibrato & LC-MS/MS & 71,7 & 239,1 \\
\hline Loratadina & LC-MS/MS & 1,9 & 6,3 \\
\hline
\end{tabular}

LC-MS/MS: cromatografia líquida acoplada à espectrometria de massas sequencial: GC-MS: cromatografia gasosa acoplada à espectrometria de massas; LD: limite de detecção; LQ: limite de quantificação.

Fonte: elaborada pelos autores. a 435,9 ng. $\mathrm{L}^{-1}$ e frequência de ocorrência de $17 \%$. Comparativamente a outras regiões do Brasil, Dias (2014) relatou valores inferiores ao da presente pesquisa na AT do Sistema Rio das Velhas/MG $\left(309,51 \mathrm{ng} \cdot \mathrm{L}^{-1}\right)$ e na AT do Sistema Guandu/RJ (17,42 ng. $\left.\mathrm{L}^{-1}\right)$. Em outros países, as concentrações foram bem inferiores às encontradas na AT da ETA Bolonha. Na Alemanha e na França os valores máximos relatados foram de 27 e 12,4 ng. L $^{-1}$ (JONES, LESTER \& VOULVOULIS, 2005; MOMPELAT, LE BOT \& THOMAS, 2009; VULLIET \& CREN-OLIVÉ, 2011; GAFFNEY et al., 2014). No Japão, Simazaki et al. (2015) mostraram valores máximos de Bezafibrato em água potável que variam de 71 a $120 \mathrm{ng} \cdot \mathrm{L}^{-1}$. Diante disso, as maiores concentrações de Bezafibrato no Brasil podem ser reflexo do consumo desse fármaco no país, já que, de acordo com o Ministério da Saúde (2020), 55,7\% da população adulta do país está com excesso de peso e $19,8 \%$ está obesa.

O fármaco Cafeína apresentou concentração de 824,4 ng. $\mathrm{L}^{-1}$ na AF. Contudo, só foi detectado na amostra da campanha 3 (período chuvoso). É provável que isso possa ter acontecido por esse composto ter apresentado concentrações inferiores aos limites de detecção e quantificação nas amostras, o que pode estar associado ao consumo da população e à tendência da Cafeína a ser hidrolisada em condições aeróbias e, portanto, ser mais facilmente degradada (RADJENOVIĆ, PETROVIĆ

Tabela 2 - Variações das concentrações e frequência de detecção dos fármacos monitorados na água bruta, filtrada e tratada do Sistema de Abastecimento Bolonha durante as 12 campanhas amostrais.

\begin{tabular}{|c|c|c|c|c|c|c|c|c|}
\hline \multirow{2}{*}{ Comp. } & \multicolumn{2}{|c|}{$A B$} & \multicolumn{2}{|c|}{$\mathrm{AF}$} & \multicolumn{2}{|c|}{ AT } & \multicolumn{2}{|c|}{ Considerando todos os pontos } \\
\hline & Conc. (ng $\left.\cdot L^{-1}\right)$ & $\mathrm{Fq}$. & Conc. (ng $\left.\cdot L^{-1}\right)$ & Fq. & Conc. (ng $\left.\cdot \mathrm{L}^{-1}\right)$ & $\mathrm{Fq}$ & Conc. (ng $\left.L^{-1}\right)$ & $\mathrm{Fq}$ \\
\hline CAF & ND & ०\% & 824,4 & $8 \%$ & ND & O\% & 824,4 & $3 \%$ \\
\hline GEN & $11,4-23,5$ & $33 \%$ & $7,1-25,8$ & $25 \%$ & 15,7 & $8 \%$ & $7,1-25,8$ & $22 \%$ \\
\hline MET & ND & O\% & ND & $0 \%$ & ND & ०\% & ND & ०\% \\
\hline PTZ & ND & O\% & ND & O\% & ND & O\% & ND & О\% \\
\hline BZF & $269,6-1364,9$ & $17 \%$ & ND & O\% & $347,6-435,9$ & $17 \%$ & $269,6-1364,9$ & $11 \%$ \\
\hline LRT & $15,7-45,0$ & $92 \%$ & $15,4-46,0$ & $100 \%$ & $15,2-24,3$ & $92 \%$ & $15,2-46,0$ & $95 \%$ \\
\hline
\end{tabular}

Comp.: composto; Conc: concentração; Fq.: frequência de detecção; AB: água bruta; AT: água tratada; AF: água filtrada; ND: não detectado (abaixo dos limites de detecção ou quantificação); CAF: Cafeína; GEN: Genfibrozila; MET: Metformina; PTZ: Prometazina; BZF: Bezafibrato; LRT: Loratadina.

Fonte: elaborada pelos autores.

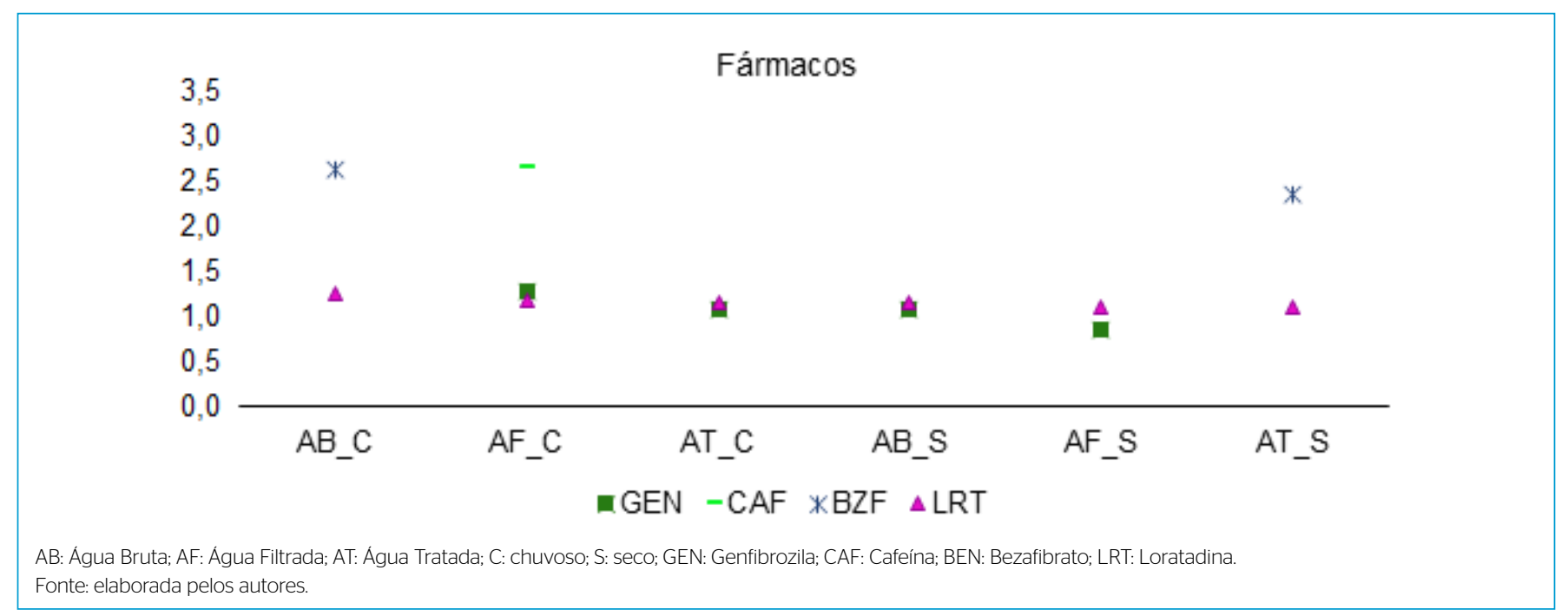

Figura 5 - Logaritmo da concentração de Genfibrozila, Cafeína, Bezafibrato e Loratadina na água bruta, filtrada e tratada nos períodos chuvoso e seco de 2018. 
\& BARCELÓ, 2009; LUO et al., 2011; SANTOS, 2018). Em comparação a outros estudos do Brasil e do mundo, em algumas pesquisas o analito Cafeína ocorreu em AB e AT em concentrações inferiores aos limites de quantificação do presente estudo. Em água superficial de sete represas de São Paulo destinadas ao abastecimento público, Shihomatsu et al. (2015) encontraram concentrações que variaram de 12 a $76 \mathrm{ng} \cdot \mathrm{L}^{-1}$, valores inferiores a $162,1 \mathrm{ng} \cdot \mathrm{L}^{-1}$ e $540,2 \mathrm{ng} \cdot \mathrm{L}^{-1}$ (limite de detecção [LD] e limite de quantificação [LQ] nesta pesquisa).

Em outros estudos também realizados em São Paulo foram encontradas variações de 61,9 a $127092 \mathrm{ng} \cdot \mathrm{L}^{-1} \mathrm{em}$ rios e represas (MONTAGNER \& JARDIM, 2011; MONTAGNER et al., 2014; CAMPANHA et al., 2015). No estado de MG foram relatadas concentrações na Bacia do Rio Doce que oscilaram entre 5,90 e 3167,44 ng.L $\mathrm{L}^{-1}$ (RODRIGUES, 2012; RODRIGUES et al., 2014). Assim, em ambos os estados foram observados valores superiores ao LQ de Cafeína do presente estudo. Isso difere de outros estudos com valores inferiores, como o de Sodré, Locatelli e Jardim (2010), que observaram concentração média de $220 \mathrm{ng} \cdot \mathrm{L}^{-1}$ em água de torneira em Campinas (SP). No contexto internacional, em Portugal, os autores Gaffney et al. (2014) observaram também valores inferiores ao LQ do presente estudo, tanto na $\mathrm{AB}$ quanto na $\mathrm{AT}$, uma vez que, nos rios Tejo e Zêzere, os autores encontraram variação de 8 a $46 \mathrm{ng} \cdot \mathrm{L}^{-1}$. Em água potável, os mesmos autores observaram concentrações entre 2,7 e $46 \mathrm{ng} \cdot \mathrm{L}^{-1}$ (GAFFNEY et al., 2014).

O fármaco Genfibrozila só ocorreu na $\mathrm{AB}$ durante o período seco, variando de 11,4 a 23,5 ng. $\mathrm{L}^{-1}$, concentrações estas bem inferiores às observadas para o Bezafibrato. Comparativamente a outros países do mundo, as concentrações de Genfibrozila observadas neste estudo foram inferiores. As médias observadas em água superficial na Itália e nos Estados Unidos variaram de 48 a $65 \mathrm{ng} \cdot \mathrm{L}^{-1}$ (MELO et al., 2009; GRENNI et al., 2013), enquanto as concentrações detectadas na Espanha variaram entre $12 \mathrm{ng} \cdot \mathrm{L}^{-1} \mathrm{e} 284 \mathrm{ng} \cdot \mathrm{L}^{-1}$ (GROS, RODRÍGUEZ-MOZAZ \& BARCELÓ, 2012). No Brasil, Reis et al. (2019) investigaram as concentrações de Genfibrozila em águas superficiais no estado de Minas Gerais, cujas médias variaram de 12 a $948 \mathrm{ng} \cdot \mathrm{L}^{-1}$. Assim, os valores foram superiores em relação aos encontrados neste trabalho.

Na pesquisa realizada por Dias (2014) também foram observadas concentrações máximas mais elevadas de Genfibrozila em águas superficiais em comparação às amostras do reservatório Bolonha. No sistema de abastecimento Rio das Velhas/MG o autor relatou concentração de 210,06 ng. $\mathrm{L}^{-1} \mathrm{e}$, no sistema Guandu/RJ, de 200,32 ng.L $\mathrm{L}^{-1}$. Entretanto, o mesmo autor observou valores mais próximos aos encontrados na $\mathrm{AB}$ do reservatório Bolonha no sistema de abastecimento Guarapiranga/SP, com variação de 1,23 a $10,37 \mathrm{ng} \cdot \mathrm{L}^{-1}$ (DIAS, 2014). Quaresma (2014) também relatou concentração máxima mais próxima às da $\mathrm{AB}$ em estudo, especificamente de 15,49 ng. $\mathrm{L}^{-1}$ de Genfibrozila na Bacia do Rio Doce/MG.

$\mathrm{Na}$ AF, a Genfibrozila oscilou entre 7,1 e 25,8 ng. $\mathrm{L}^{-1}$, com frequência de ocorrência de $25 \%$. Na AT, o composto só ocorreu em uma amostra do período chuvoso (Figura 5), com concentração de 15,7 ng.L-1. Em comparação a outros estudos no Brasil realizados em AT, na região Sudeste pesquisas mostraram médias de 3,74 a 21,28 ng. $\mathrm{L}^{-1}$ e concentrações máximas que variaram entre 29,82 e $293 \mathrm{ng} \cdot \mathrm{L}^{-1}$ (DIAS, 2014; REIS et al., 2019). Assim, a maior parte dos valores foi superior ao da presente pesquisa. Em outros países, como a Espanha, as concentrações médias em AT também foram inferiores e oscilaram entre 2 e $8 \mathrm{ng} \cdot \mathrm{L}^{-1}$ (GROS, RODRÍGUEZ-MOZAZ \& BARCELÓ, 2012; CARMONA, ANDREU \& PICÓ, 2014; COUTO, LANGE \& AMARAL, 2019). As concentrações máximas em Portugal e no Canadá foram superiores às relatadas na presente pesquisa, sendo de, respectivamente, 18 e $70 \mathrm{ng} \cdot \mathrm{L}^{-1}$ (JONES, LESTER \& VOULVOULIS, 2005; GAFFNEY et al., 2014).

$\mathrm{O}$ fármaco Loratadina foi o que apresentou comportamento mais constante no sistema de abastecimento de água Complexo Bolonha (Tabela 2). $\mathrm{Na} \mathrm{AB}$, apresentou variação de 15,7 a 45,0 ng. $\mathrm{L}^{-1}$. Comparativamente a estudos realizados previamente no Brasil, os autores Couto et al. (2020) quantificaram Loratadina em concentrações abaixo do $\mathrm{LD}\left(\mathrm{LD}=13,6 \mathrm{ng} \cdot \mathrm{L}^{-1}\right)$ na Bacia do Rio Doce em MG, inferiores às obtidas no presente estudo. Shihomatsu et al. (2015) observaram concentrações em níveis abaixo do $\mathrm{LD}$ e do $\mathrm{LQ}\left(\mathrm{LD}=1,4 \mathrm{ng} \cdot \mathrm{L}^{-1}\right.$; $\mathrm{LQ}=12,6 \mathrm{ng} \cdot \mathrm{L}^{-1}$ ) também em sete represas de São Paulo. Contudo, Reis et al. (2019) observaram na Região Metropolitana de Belo Horizonte/MG concentrações máximas em AB, que variaram de 56 a $486 \mathrm{ng} \cdot \mathrm{L}^{-1}$. Nesse caso, as concentrações máximas foram maiores em relação às encontradas neste estudo. Em outras áreas do mundo, as máximas concentrações de Loratadina identificadas foram inferiores. No rio Langat (Malásia) e nos rios Ebro e Jarama (Espanha), os valores foram de, respectivamente, $3 \mathrm{ng} \cdot \mathrm{L}^{-1}(<\mathrm{LD}), 3,96 \mathrm{ng} \cdot \mathrm{L}^{-1} \mathrm{e}$ $24 \mathrm{ng} \cdot \mathrm{L}^{-1}$ (AL-ODAINI et al., 2010; VALCÁRCEL et al., 2011; LÓPEZ-SERNA, PETROVIĆ \& BARCELÓ, 2012).

$\mathrm{Na} \mathrm{AF}$, o Loratadina apresentou ocorrência que oscilou de 15,4 a 46,0 ng. $\mathrm{L}^{-1}$. $\mathrm{Na}$ AT as concentrações foram inferiores, com variação de 15,2 a $24,3 \mathrm{ng} \cdot \mathrm{L}^{-1}$. Em relação ao estudo de Santos (2018), que investigou águas tratadas de ETA nas regiões Nordeste, Sudeste e Sul do Brasil, não houve detecção de Loratadina em AT nas duas primeiras, entretanto foi observada concentração de $17 \mathrm{ng} \cdot \mathrm{L}^{-1}$ em AT na última, valor semelhante aos deste estudo. Algo diferente ocorreu no estudo de Reis et al. (2019), que pesquisaram a ocorrência do fármaco em AT na saída de ETA de MG e relataram concentrações máximas superiores, com variação de 55 a $67 \mathrm{ng} \cdot \mathrm{L}^{-1}$.

$\mathrm{Na}$ Espanha e na Suécia, alguns autores mostraram que o Loratadina não foi detectado em água potável, ou seja, estava em concentrações abaixo do LD e do LQ dos métodos de análise (VALCÁRCEL et al., 2011; GROS, RODRÍGUEZMOZAZ \& BARCELÓ, 2012; PETROVIĆ et al., 2014). Diante disso, observam-se maiores concentrações de Loratadina no Brasil assim como no Reservatório Bolonha em comparação a outros países. Isso pode ser resultado das alergias que atingem cerca de $30 \%$ da população nacional (ASBAI, 2020). Além disso, segundo a Associação Brasileira de Alergia e Imunologia (ASBAI, 2020), 50\% da população mundial apresentará alguma alergia até 2050.

Pela observação dos fármacos na $\mathrm{AB}$ do reservatório Bolonha, notam-se distinções tanto entre as concentrações quanto na sazonalidade com que cada um ocorre. As principais diferenças nas concentrações e na ocorrência podem ser provenientes do padrão de consumo, o que é reflexo das doenças mais comuns e consequência do estilo de vida populacional. As concentrações também são resultado da não degradação desses compostos, da falta de tratamento de efluentes, do uso e da ocupação do solo e da população residente próximo ao reservatório Bolonha. Além disso, mas igualmente importante, devem-se levar em consideração as condições hídricas da cidade de Belém (PA) e a bacia hidrográfica. Dessa forma, fatores como vazão de rio e índice de pluviosidade da área de estudo podem ter determinado a sedimentação e a degradação dos fármacos ou até mesmo a diluição, que variam de acordo com as características do composto e da localidade.

Pela avaliação dos resultados, observa-se que há ocorrência de fármacos na $\mathrm{AT}$ e AF, mesmo que em menor concentração que na AB. Nota-se também que a 
maior parte dos fármacos investigados foram relatados em maiores concentrações nos estudos realizados no Brasil do que no contexto internacional. Isso pode ser resultado do tipo de tratamento de água empregado no Brasil em comparação ao dos outros países, como também da falta de saneamento básico e da falta de tratamento de efluentes em muitos municípios. Diante disso, é imprescindível ressaltar que o Brasil é um país de dimensões continentais, e cada região dispõe de diferentes porcentagens de acesso ao saneamento. A região Norte não possui condições de saneamento adequadas em muitos de seus municípios, principalmente em relação à coleta e ao tratamento de efluentes.

Pelos resultados obtidos, é preciso levar em conta a densidade populacional e as áreas de baixa renda per capita próximas à captação de água, o que pode indicar maior vulnerabilidade da água superficial à contaminação. Essa vulnerabilidade é observada na área de estudo, pois o crescimento populacional próximo ao sistema de abastecimento de água Complexo Bolonha acompanhou o crescimento da RMB. Diante disso e da falta de tratamento de efluentes domésticos, fica evidente a influência antrópica que o reservatório Bolonha vem sofrendo. Apesar de estar contido em uma área de proteção, recebe muitas contribuições de efluentes domésticos.

Na Tabela 3, têm-se as eficiências de remoção da ETA Bolonha: pós-filtração $\left(\mathrm{ER}_{\mathrm{Pós}-\text {-Filt }}\right)$, pós-cloração (desinfecção) $\left(\mathrm{ER}_{\mathrm{Pós}-\mathrm{Clor}}\right)$ e ao fim do tratamento de ciclo completo $\left(\mathrm{ER}_{\mathrm{Total}}\right)$. Todas as eficiências foram calculadas nos períodos chuvoso, seco e considerando-se os dois períodos (anual de 2018). Nos casos em que as concentrações estiveram abaixo do LD ou do LQ, a eficiência de remoção foi calculada utilizando-se os valores estimados para os dados citados, ou seja, consideraram-se os valores correspondentes a LD/2 ou (LD + LQ)/2 no caso de concentrações inferiores aos LD ou LQ, respectivamente. Entretanto, se o composto não foi detectado acima dos limites em nenhum dos pontos, sua remoção não foi calculada.

A eficiência de remoção após a etapa de filtração $\left(E_{\text {Pós-Filt }}\right)$ teve variação de $22 \%$ (Loratadina) a 96\% (Bezafibrato) no período chuvoso. Já no período seco as remoções foram inferiores, com percentuais de 15\% (Loratadina) a $47 \%$ (Genfibrozila). As remoções foram superiores no período chuvoso, pois justamente nesse período ocorrem maiores remoções de turbidez pela filtração em comparação às do período seco, já que a maior incidência de chuva ocasiona maiores concentrações de sólidos suspensos na $\mathrm{AB}$. Sendo assim, os fármacos adsorvidos nesses sólidos acabam sendo removidos em maior porcentagem pela etapa de filtração. Já em relação ao período anual, as remoções foram de $13 \%$ para o Genfibrozila, de $18 \%$ para o Loratadina e de $96 \%$ para o Bezafibrato. Segundo revisão de literatura feita pelos autores Lima et al. (2017), as etapas de coagulação, floculação e decantação, que por sua vez antecedem a etapa de filtração, apresentam baixa eficiência $(<50 \%)$ de remoção para vários microcontaminantes. Dessa forma, as melhores eficiências de remoção após esses processos (coagulação, floculação e decantação) são alcançadas geralmente para compostos que têm caráter hidrofóbico, pois eles geralmente possuem a tendência de se adsorverem em sólidos suspensos.

De todos os compostos avaliados na etapa de remoção pós-filtração (Bezafibrato, Genfibrozila e Loratadina), somente o Bezafibrato apresentou degradação maior que 50\%, remoção de especificamente $96 \%$ durante o

Tabela 3 - Remoção de fármacos na estação de tratamento de água Bolonha em função da etapa do tratamento.

\begin{tabular}{|c|c|c|c|c|c|c|}
\hline Compostos detectados & Méd de conc. (ng. $\left.\mathrm{L}^{-1}\right)$ & Méd de conc. (ng $\mathrm{L}^{-1}$ ) & Méd de conc. (ng $\left.\cdot \mathrm{L}^{-1}\right)$ & $E R_{\text {Pós-Filt. }}(\%)$ & $\mathrm{ER}_{\text {Pós.Clor. }}(\%)$ & $E R_{\text {Total }}(\%)$ \\
\hline CAF & $81,1(<\mathrm{LD})$ & 824,4 & $81,1(<\mathrm{LD})$ & - & 90 & 0 \\
\hline GEN & $\mathrm{O}, 2(<\mathrm{LD})$ & 25,8 & 15,7 & - & 39 & - \\
\hline BEZ & 817,3 & $35,9(<$ LD $)$ & $35,9(<\mathrm{LD})$ & 96 & 0 & 96 \\
\hline \multicolumn{7}{|c|}{ Período seco 2018} \\
\hline \multirow{2}{*}{ Compostos detectados } & $A B$ & AF & AT & \multirow{2}{*}{$\mathrm{ER}_{\text {Pos.Fit. }}$ (\%) } & \multirow{2}{*}{$\mathrm{ER}_{\text {Pós-Clor. }}(\%)$} & \multirow{2}{*}{$\mathrm{ER}_{\text {Total }}(\%)$} \\
\hline & Méd de conc. (ng: $\left.\mathrm{L}^{-1}\right)$ & Méd de conc. (ng. $\left.\mathrm{L}^{-1}\right)$ & Méd de conc. (ng $\left.\cdot \mathrm{L}^{-1}\right)$ & & & \\
\hline GEN & 16,5 & 8,8 & $0,2(<L D)$ & 47 & 98 & 99 \\
\hline \multirow{2}{*}{ Compostos detectados } & $\mathrm{AB}$ & $\mathrm{AF}$ & AT & \multirow{2}{*}{$E R_{\text {Pós.Filt. }}(\%)$} & \multirow{2}{*}{$\mathrm{ER}_{\text {Pós-Clor. }}(\%)$} & \multirow{2}{*}{$E R_{\text {Total }}(\%)$} \\
\hline & Méd de conc. (ng. $\left.\mathrm{L}^{-1}\right)$ & Méd de conc. (ng: $\left.\mathrm{L}^{-1}\right)$ & Méd de conc. (ng: $\left.\mathrm{L}^{-1}\right)$ & & & \\
\hline CAF & $81,1(<$ LD) & 824,4 & $81,1(<\mathrm{LD})$ & - & 90 & 0 \\
\hline GEN & 16,5 & 14,4 & 15,7 & 13 & - & 5 \\
\hline BEZ & 817,3 & $35,9(<\mathrm{LD})$ & 391,8 & 96 & & 52 \\
\hline LRT & 24,7 & 20,3 & 18,2 & 18 & 10 & 26 \\
\hline
\end{tabular}

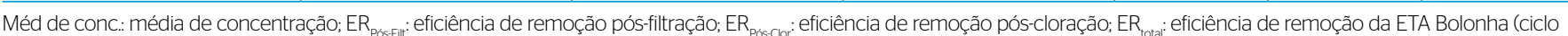
completo); : valores negativos; < LD: abaixo do limite de detecção; AB: água bruta; AF: água filtrada; AT: água tratada; GEN: Genfibrozila; BZF: Bezafibrato; LRT: Loratadina; CAF: cafeína. Fonte: elaborada pelos autores. 
período chuvoso. Isso, possivelmente, porque esse composto (Bezafibrato) possui em relação aos investigados elevada taxa de adsorção em sólidos suspensos, comportamento já verificado pelos pesquisadores Liu et al. (2018). Por conseguinte, como as etapas de tratamento que antecedem a filtração têm por objetivo principal a remoção de sólidos suspensos além de parte de sólidos dissolvidos, até a filtração a ETA Bolonha demonstrou alta taxa de remoção para o Bezafibrato. Além disso, as taxas de remoções verificadas foram maiores durante o período chuvoso, período em que foram observados maiores valores de turbidez na $\mathrm{AB}$ e na $\mathrm{AF}$.

A remoção pós-desinfecção $\left(\mathrm{ER}_{\text {Pós-Clor }}\right)$ foi eficiente em $17 \%$ para Loratadina, em 39\% para Genfibrozila e em $90 \%$ para Cafeína no período de maiores precipitações. No período com menores precipitações as remoções foram de $1 \%$ para Loratadina e de $98 \%$ para Genfibrozila. Já a remoção anual oscilou entre $10 \%$ (Loratadina) e 90\% (Cafeína). Como pôde ser observado, para os fármacos Genfibrozila e Cafeína foram obtidas altas taxas de remoção ( $\geq 90 \%)$. Assim, pode-se concluir que a etapa de desinfecção por cloro gás da ETA Bolonha pôde oxidar altas taxas de alguns microcontaminantes em estudo, excetuando-se o fármaco Loratadina, que apresentou menor taxa de remoção $(<20 \%)$.

Segundo Rigobello et al. (2013) e Lima et al. (2017), a etapa de desinfecção depende principalmente de dois fatores: poder oxidante (determinado pelo potencial de redução $-\varepsilon$ ) do desinfetante e do tempo de contato. Esses fatores foram verificados nas pesquisas de Pereira (2011) e Rigobello et al. (2013), que constataram altas taxas de remoção para os compostos Estrona e Diclofenaco (> 97\%). Entretanto, nos estudos mencionados, o tempo de contato na desinfecção foi muito superior ( 24 horas) ao utilizado em uma ETA de ciclo completo como a ETA Bolonha, que tem como tempo mínimo de contato aproximadamente 30 minutos. Além disso, é necessário investigar a remoção de metabólitos desses compostos e a formação de subprodutos após a etapa de cloração que alguns autores já relataram (PEREIRA, 2011; RIGOBELLO et al., 2013; SOUZA, 2014), já que pouco se sabe sobre a toxicidade desses subprodutos.

Ao fim do tratamento de ciclo completo na ETA Bolonha foi observado que, no período chuvoso, as porcentagens de remoção $\left(\mathrm{ER}_{\text {Total }}\right)$ variaram entre 36\% (Loratadina) e 96\% (Bezafibrato). Já no período seco, as remoções foram de 16\% (Loratadina) e 99\% (Genfibrozila). Na Figura 5, tem-se o gráfico do logaritmo das concentrações de fármacos por período (chuvoso e seco) e por ponto de coleta $(\mathrm{AB}, \mathrm{AF}, \mathrm{AT})$. Fica visível pelo gráfico que há ocorrência de Genfibrozila na $\mathrm{AT}$, mesmo que não haja presença detectável na $\mathrm{AB}$ durante o período chuvoso. Isso também ocorre com o Bezafibrato no período seco, que só foi detectado na AT. Maiores concentrações na AT que na $\mathrm{AB}$ de alguns compostos foram verificadas também na pesquisa de Dias (2014).

$\mathrm{Na}$ avaliação anual da remoção ao término do tratamento, foram verificadas eficiências de remoção médias de 5\% para o Genfibrozila, de $26 \%$ para o Loratadina e de $52 \%$ para o Bezafibrato. No tratamento de água de ciclo completo, o fármaco para o qual se observou maior eficiência de remoção foi o Bezafibrato, tanto na etapa pós-filtração quanto ao fim do tratamento. Isso mostra que, mesmo que esse fármaco tenha apresentado concentrações muito elevadas na $\mathrm{AB}$ em relação aos outros investigados, foi o que apresentou maiores remoções ao longo das etapas de tratamento da ETA Bolonha. Na Figura 6, apresenta-se gráfico boxplot da ocorrência dos fármacos Genfibrozila, Bezafibrato e Loratadina na $\mathrm{AB}$, AF e AT, e é

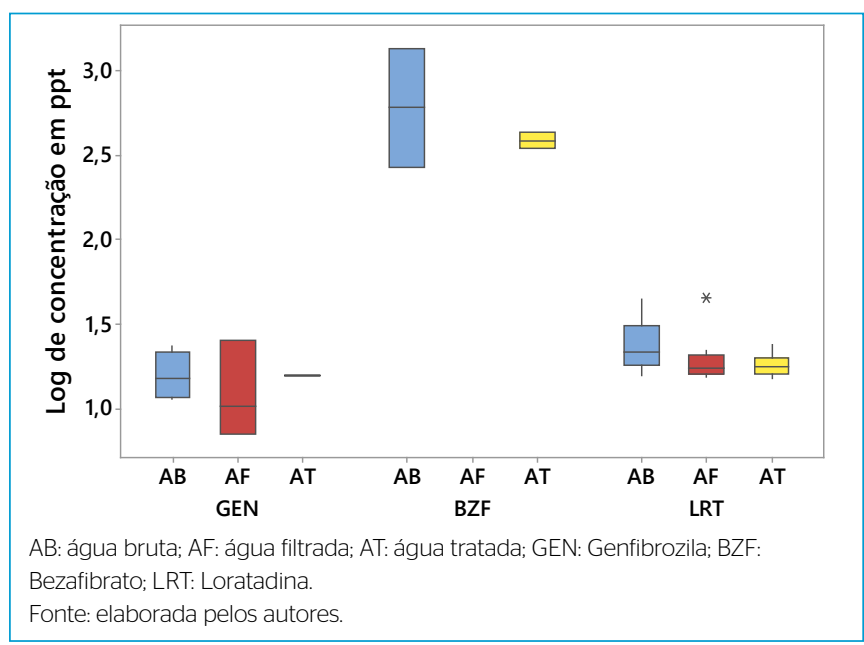

Figura 6 - Boxplot de Genfibrozila, Bezafibrato e Loratadina na água bruta, filtrada e tratada.

possível visualizar a diminuição da concentração de fármacos ao longo do processo de tratamento de água.

Com base nos resultados, conclui-se que o tratamento de ciclo completo não consegue remover eficientemente os compostos de preocupação emergente estudados. Observa-se que os processos de uma ETA são mais eficientes para compostos hidrofóbicos, que têm tendência de se adsorverem aos sólidos suspensos e, por isso, serem removidos de roldão durante a remoção da turbidez. Além disso, ao final do tratamento há a formação de subprodutos resultantes da cloração, que precisam ser investigados quanto à sua toxicidade. Assim, pela observação dos resultados, a remoção é influenciada não só pelo tipo de tratamento empregado, mas também pelas propriedades físico-químicas dos fármacos, pelos parâmetros operacionais e pelas características da água, e as maiores remoções foram obtidas durante o período chuvoso.

\section{CONCLUSÕES}

Os resultados obtidos indicaram que o sistema de captação e tratamento de água Bolonha apresentou influência antrópica, dada principalmente pelo lançamento de efluentes domésticos brutos no reservatório Bolonha, pois o sistema em estudo está inserido em uma área que sofre com o aumento populacional desordenado. No reservatório Bolonha, o fármaco Loratadina manteve ocorrência constante em ambos os períodos amostrais (seco e chuvoso). Já para o Bezafibrato e o Genfibrozila, concluiu-se que houve distinções entre a ocorrência e as concentrações desses fármacos em relação à sazonalidade da região em estudo.

Na ETA Bolonha, nas AF e AT, observou-se que a maior parte dos fármacos ocorreu em menor concentração que na $\mathrm{AB}$. As eficiências globais de remoção $\left(\mathrm{ER}_{\text {Total }}\right.$ ) variaram entre $5 \%$ (Genfibrozila) e $52 \%$ (Bezafibrato), e as eficiências de remoção na etapa de desinfecção (ER Pós-Clor) $_{\text {. }}$ variaram de $10 \%$ (Loratadina) a 90\% (Cafeína). Assim, concluiu-se que o tratamento de ciclo completo empregado na ETA Bolonha não foi eficiente para a remoção da maioria dos compostos de preocupação emergente estudados, e que atenção deve ser dada à potencial formação de compostos clorados tóxicos na etapa de desinfecção. 


\section{AGRADECIMENTOS}

Os autores agradecem às seguintes agências pelo suporte financeiro: Coordenação de Aperfeiçoamento de Pessoal de Nível Superior (CAPES), Fundação de Amparoà Pesquisa do Estado de Minas Gerais (FAPEMIG), Conselho Nacional de Desenvolvimento Científico e Tecnológico (CNPq), Fundação Nacional de Saúde (FUNASA), Universidade Federal do Pará (UFPA) e Universidade Federal de Ouro Preto (UFOP).

\section{CONTRIBUIÇÃO DOS AUTORES}

Chaves, J. R.: conceituação, coleta de dados, análise formal, metodologia, escrita primeira redação - revisão e edição. Mendonça, N.: revisão. Teixeira, L.C.: conceituação, curadoria de dados, supervisão, escrita - revisão e edição. Aquino, S. F.: conceituação, coordenação, obtenção de financiamento, metodologia, supervisão, escrita.

\section{REFERÊNCIAS}

AL-ODAINI, N. A.; ZAKARIA, M. P.; YAZIZ, M. I.; SURIF, S. Multi-residue analytical method for human pharmaceuticals and synthetic hormones in river water and sewage effluents by solid-phase extraction and liquid chromatographytandem mass spectrometry. Journal of Chromatography A, v. 1217, n. 44 , p. 6.791-6.806, 2010. https://doi.org/10.1016/j.chroma.2010.08.033

ASSOCIAÇÃO BRASILEIRA DE ALERGIA E IMUNOLOGIA (ASBAI). Alergia - Perguntas e Respostas. Disponível em: http://asbai.org.br/category/livrosmaterial-educativo/. Acesso em: 3 ago. 2020.

BELÉM. Plano Municipal de Saneamento Básico de Abastecimento de Água e Esgotamento Sanitário de Belém - Pará, 2015. Agência Reguladora Municipal de Belém. Disponível em: http://www.belem.pa.gov. br/arbel/?page_id=723. Acesso em: 3 ago. 2020 .

BISOGNIN, R. P.; WOLFF, D. B.; CARISSIMI, E. Revisão sobre fármacos no ambiente. Revista DAE, v. 66, n. 210, p. 78-95, 2018. https://doi.org/10.4322/ dae.2018.009

BRANCHET, P.; CASTRO, N. A.; FENET, H.; GOMEZ, E.; COURANT, F.; SEBAG, D.; GARDON, J.; JOURDAN, C.; NGATCHA, B. N.; KENGNE, I.; CADOT, E.; GONZALEZ, C. Anthropic impacts on Sub-Saharan urban water resources through their pharmaceutical contamination (Yaoundé Center Region, Cameroon). Science of the Total Environment, v. 660, p. 886-898, 2019. https://doi.org/10.1016/j.scitotenv.2018.12.256

CAMPANHA, M. B.; AWAN, A. T.; SOUZA, D. N. R.; GROSSELI, G. M.; MOZETO, A. A.; SADINI, P. S. A 3-year study on occurrence of emerging contaminants in an urban stream of São Paulo State of Southeast Brazil. Environmental Science and Pollution Research, v. 22, n. 10, p. 7.936-7.947, 2015. https://doi. org/10.1007/s11356-014-3929-x

CARMONA, E.; ANDREU, V:; PICO, Y. Occurrence of acidic pharmaceuticals and personal care products in Turia River Basin: From waste to drinking water. Science of the Total Environment, v. 484, p. 53-63, 2014. https://doi. org/10.1016/j.scitotenv.2014.02.085

CASTIGLIONI, S.; DAVOLI, E.; RIVA, F.; PALMIOTTO, M.; CAMPORINI, P.; MANENTI, A.; ZUCCATO, E. Mass balance of emerging contaminants in the water cycle of a highly urbanized and industrialized area of Italy. Water Research, v. 131, p. 287-298, 2018. https://doi.org/10.1016/j.watres.2017.12.047

COMPANHIA AMBIENTAL DO ESTADO DE SÃO PAULO (CETESB). Guia Nacional de Coleta e Preservação de Amostras - Água, Sedimento, Comunidades Aquáticas e Efluentes Liquidos. 2ª ed. Brasília: CETESB; ANA, 2011

COUTO, C. F.; SANTOS, A. V.; AMARAL, M. C. S.; LANGE, L. C.; ANDRADE, L. H.; FOUREAUX, A. F. S.; FERNANDES, B. S. Assessing potential of nanofiltration, reverse osmosis and membrane distillation drinking water treatment for pharmaceutically active compounds (PhACs) removal. Journal of Water Process Engineering, v. 33, p. 1-12, 2020. https://doi.org/10.1016/j. jwpe.2019.101029

COUTO, C. F.; LANGE, L. C.; AMARAL, M. C. S. Occurrence, fate and removal of pharmaceutically active compounds (PhACs) in water and wastewater treatment plants - A review. Journal of Water Process Engineering, v. 32 p. 1-17, 2019. https://doi.org/10.1016/j.jwpe.2019.100927

DIAS, R. V. A. Avaliação da ocorrência de microcontaminantes emergentes em sistemas de abastecimento de água e da atividade estrogênica do etinilestradiol. Dissertação (Mestrado EM em Saneamento, Meio Ambiente e Recursos Hídricos) - Universidade Federal de Minas Gerais, Belo Horizonte, 2014

GAFFNEY, V. J.; ALMEIDA, C. M. M.; RODRIGUES, A.; FERREIRA, E.; BENOLIEL, M. J.; CARDOSO, V. V. ScienceDirect Occurrence of pharmaceuticals in a water supply system and related human health risk assessment. Water Research, v. 72, p. 199-208, 2014. https://doi.org/10.1016/j.watres.2014.10.027

GARCIA-GIL, A.; SCHNEIDER, E. G; MEJIAS, M.; BARCELO, D.; VÁZQUEZ SUÑÉ, E.; DIAZ-CRUZ, S. Occurrence of pharmaceuticals and personal care products in the urban aquifer of Zaragoza (Spain) and its relationship with intensive shallow geothermal en- ergy exploitation. Journal of Hydrology, v. 566, p. 629-642, 2018. https://doi.org/10.1016/j.jhydrol.2018.09.066

GOOGLE. Google Earth. Disponível em: https://www.google.com.br/int//ptBR/earth/. Acesso em: 13 fev. 2020.

GRENNI, P. et al. Degradation of Gemfibrozil and Naproxen in a river water ecosystem. Microchemical Journal, v. 107, p. 158-164, 2013. http://doi. org/10.1016/j.microc.2012.06.008

GROS, M.; RODRÍGUEZ-MOZAZ, S.; BARCELÓ, D. Fast and comprehensive multi-residue analysis of a broad range of human and veterinary pharmaceuticals and some of their metabolites in surface and treated waters by ultra-high-performance liquid chromatography coupled to quadrupole-linear ion trap tandem. Journal of Chromatography A, v. 1.248, p. 104-121, 2012. https://doi.org/10.1016/j.chroma.2012.05.084

GUTIERREZ, C. B. B.; RIBEIRO, H. M. C.; MORALES, G. P.; GUTIERREZ, D. M. G.; DANTOS, L. S.; PAULA, M. T. Análise espaço-temporal do uso e cobertura do solo no interior da APA Belém e correlação com os parâmetros de água dos seus mananciais. Revista Brasileira de Geografia Física, v. 10, n. 2, p. 521-534, 2017. https://doi.org/10.5935/1984-2295.20170033

HIDROWEB. Agência Nacional de Águas (ANA). Sistema Nacional de Informações sobre Recursos Hídricos (SNIRH). Disponivel em: http://www. snirh.gov.br/hidroweb/apresentacao. Acesso em: 20 jan. 2020. 
JONES, O. A.; LESTER, J. N.; VOULVOULIS, N. Pharmaceuticals: A threat to drinking water? Trends in Biotechnology, v. 23, n. 4, p. 163-167, 2005. https:// doi.org/10.1016/j.tibtech.2005.02.001

KEITH, L. H. Recent advances in the identification and analysis of organic pollutants in water. Life Sciences, v. 19, n. 11, p. 1.631-1.635, 1976. https://doi. org/10.1016/0024-3205(76)90067-9

LIMA, D. R. S.; TONUCCI, M. C.; LIBÂNIO, M.; AQUINO, S. F. Fármacos e desreguladores endócrinos em águas brasileiras: ocorrência e técnicas de remoção. Engenharia Sanitaria e Ambiental, v. 22, n. 6, p. 1.043-1.054, 2017. https://doi.org/10.1590/S1413-41522017165207

LIU, J.; DAN, X.; LU, G.;SHEN, J:; WU, D.; YAN, Z. Investigation of pharmaceutically active compounds in an urban receiving water: Occurrence, fate and environmental risk assessment. Ecotoxicology and Environmental Safety, v. 154, p. 214-220, 2018. https://doi.org/10.1016/j.ecoenv.2018.02.052

LÓPEZ-SERNA, R.; PETROVIĆ, M.; BARCELÓ, D. Occurrence and distribution of multi-class pharmaceuticals and their active metabolites and transformation products in the Ebro River basin (NE Spain). Science of the Total Environment, v. 440, p. 280-289, 2012. https://doi.org/10.1016/j. scitotenv.2012.06.027

LUO, Y.; XU, L.; RYSZ, M.; WANG, Y.; ZHANG, H.; ALVAREZ, P. J. J. Occurrence and transport of tetracycline, sulfonamide, quinolone, and macrolide antibiotics in the haihe River basin, China. Environmental Science and Technology, v. 45, p. 1.827-1.833, 2011. https://doi.org/10.1021/es104009s

MELO, S. A. S.; TROVÓ, A. G.; BAUTITZ, I. R.; NOGUEIRA, R. F. P. Degradação de fármacos residuais por processos oxidativos avançados. Quimica Nova, v.32, n. 1, p. 188-197, 2009. https://doi.org/10.1590/S0100-40422009000100034

MINISTÉRIO DA SAÚDE. Obesidade e excesso de peso na população de Belém. Governo Federal, Brasília. Disponível em: https://www.saude.gov.br/ noticias/agencia-saude/43681-com-obesidade-e-excesso-de-peso-estaveispopulacao-de-belem-passa-a-adotar-praticas-saudaveis. Acesso em: 10 set. 2020 .

MINISTÉRIO DA SAÚDE DO. Obesidade e excesso de peso da polução do Brasil. Governo Federal, Brasília. Disponível em: saude.gov.br/noticias/ agencia-saude/46485-mais-da-metade-dos-brasileiros-esta-acima-do-peso. Acesso em: 9 set. 2020.

MOMPELAT, S.; LE BOT, B.; THOMAS, O. Occurrence and fate of pharmaceutical products and by-products, from resource to drinking water. Environment International, v. 35, n. 5, p. 803-814, 2009. https://doi. org/10.1016/j.envint.2008.10.008

MONTAGNER, C. C.; JARDIM, W. F.; VON DE OTHE, P. C.; UMBUZEIRO, G. A. Occurrence and potential risk of triclosan in freshwaters of São Paulo, Brazil-the need for regulatory actions. Environmental Science and Pollution Research, v. 21, n. 3, p. 1.850-1.858, 2014. https://doi.org/10.1007/s11356-0132063-5

MONTAGNER, C. C.; JARDIM, W. F. Spatial and seasonal variations of pharmaceuticals and endocrine disruptors in the Atibaia River, São Paulo State (Brazil). Journal of the Brazilian Chemical Society, v. 22, n. 8, p. 1.452-1.462, 2011. https://doi.org/10.1590/S0103-50532011000800008

MONTAGNER, C. C.; VIDAL, C:; ACAYABA, R. D. Contaminantes emergentes em matrizes aquáticas do Brasil: cenário atual e aspectos analíticos, ecotoxicológicos e regulatórios. Quimica Nova, v. 40, n. 9, p. 1.094-1110, 2017. https://doi.org/10.21577/0100-4042.20170091
OSAWA, R. A.; IDE, A. H.; SAMPAIO, N. M. F. M.; AZEVEDO. J. C. R. Determinação de fármacos anti-hipertensivos em águas superficiais na região metropolitana de Curitiba. Revista Brasileira de Recursos Hídricos, v. 20, n. 4, p. 1.039-1.050, 2015. http://doi.org/10.21168/rbrh. v20n4.p1039-1050

PARÁ. Decreto Estadual no 1552, de 3 de maio de 1993 - Dispõe sobre a Criação do Parque Ambiental de Belém e dá outras providências. Secretaria de Meio Ambiente e Sustentabilidade, 1993. Disponível em: https://www. semas.pa.gov.br/1993/05/03/9614/. Acesso em: 9 set. 2020.

PARÁ. Apresentação. Secretaria de Estado de Meio Ambiente e Sustentabilidade. Disponível em: https://www.semas.pa.gov.br/diretorias/ areas-protegidas/peut/apresentacao/. Acesso em: 17 abr. 2019

PEREIRA, R. D. O. Formação de subprodutos do estrona e 17b-estradiol na oxidaçao utilizando cloro e ozônio em água. Tese (Doutorado em Engenharia) - Escola de Engenharia de São Carlos, Universidade de São Paulo, São Carlos, 2011.

PETROVIĆ, M.: ŠKRBIĆ, B.; ŽIVANČEV, J.; FERRANDO-CLIMENT, L.; BARCELO D. Determination of 81 pharmaceutical drugs by high performance liquid chromatography coupled to mass spectrometry with hybrid triple quadrupole-linear ion trap in different types of water in Serbia. Science of the Total Environment, v. 468-469, p. 415-428, 2014. https://doi.org/10.1016/j. scitotenv.2013.08.079

QUARESMA, A. V. Monitoramento de Microcontaminantes Orgânicos por Métodos Cromatográficos Acoplados à Espectrometria de Massa e Elementos Inorgânicos por Fluorescência de Raios - X por Reflexão Total nas Águas da Bacia do Rio Doce. Dissertação (Mestrado em Engenharia Ambiental) - Universidade Federal de Ouro Preto, Ouro Preto, 2014

RADJENOVIĆ, J.; PETROVIĆ, M.; BARCELO, D. Fate and distribution of pharmaceuticals in wastewater and sewage sludge of the conventional activated sludge (CAS) and advanced membrane bioreactor (MBR) treatment. Water Research, v. 43, n. 3, p. 831-841, 2009. https://doi. org/10.1016/j.watres.2008.11.043

REIS, E. O.; FOUREAUX, A. F. S.; RODRIGUES, J. S.; MOREIRA, V. R.; LEBRON, Y. A. R.; SANTOS, L. V. S.; AMARAL, M. C. S.; LANGE, L. C. Occurrence, removal and seasonal variation of pharmaceuticals in Brasilian drinking water treatment plants. Environmental Pollution, v. 250, p. 773-781, 2019. https:// doi.org/10.1016/j.envpol.2019.04.102

RIGOBELLO, E. S.; DANTAS, A. D. B.; BERNARDO, L. D.; VIEIRA, E. M. Removal of diclofenac by conventional drinking water treatment processes and granular activated carbon filtration. Chemosphere, v. 92, n. 2, p. 184-191, 2013. https://doi.org/10.1016/j.chemosphere.2013.03.010

RODRIGUES, K. L. T. Desenvolvimento de metodologia analítica para determinação simultânea de microcontaminantes emergentes em águas superficiais por cromatografia líquida acoplada à espectrometria de massas. Dissertação (Mestrado em Engenharia Ambiental) - Universidade Federal de Ouro Preto, Ouro Preto, 2012.

RODRIGUES, K. L. T.; SANSON, A. L.; QUARESMA, A. V.; PAIVA G. A.; ALFONSO, R. J. C Chemometric approach to optimize the operational parameters of ESI for the determination of contaminants of emerging concern in aqueous matrices by LC-IT-TOF-HRMS. Microchemical Journal, v. 117, p. 242-249, 2014. https://doi.org/10.1016/j. microc.2014.06.017 
SANSON, A. L. Estudo da extração e desenvolvimento de metodologia para determinação simultânea de microcontaminantes orgânicos em água superficial por GC-MS e métodos quimiométricos. Dissertação (Mestrado em Engenharia Ambiental) - Universidade Federal de Ouro Preto, Ouro Preto, 2012.

SANSON, A. L.; BAETA, B. E. L.; RODRIGUES, K. L. T.; AFONSO, R. J. C. F. Equipamento de baixo custo para extração em fase sólida em amostras aquosas de grande volume utilizando pressão positiva de N2. Quimica Nova, v. 37, n. 1, p. 150-152, 2014. https://doi.org/10.1590/s0100-40422014000100024

SANTOS, A. V. Environmental and human health risk assessment of pharmaceuticals in surface and drinking water treated by conventional and membrane separation processes. [s...] Dissertação (Mestrado em Saneamento, Meio Ambiente e Recursos Hídricos) - Universidade Federal de Minas Gerais, Belo Horizonte, 2018.

SECRETARIA DE ESTAdo DE MEIO AMBIENTE (SEMA). Plano de Manejo do Parque Estadual do Utinga - Resumo Executivo. $1^{\text {a }}$ ed. Belém: SEMA; IMAZON, 2013.

SHIHOMATSU, H. M.; MARTINS, E. A. J.; COTRIM, M. E. B.; LEBRE, D. T.; PIRES, M. A. F. Avaliação da ocorrência de fármacos nas águas de represas do estado de São Paulo, SP, Brasil. COPEC, p. 237-241, 2015. https://doi. org/10.14684/SHEWC.15.2015.237-241

SIMAZAKI, D.; KUBOTA, R.; SUZUKI, T.; AKIBA, M.; NISHIMURA, T.; KUNIKANE, S. Occurrence of selected pharmaceuticals at drinking water purification plants in Japan and implications for human health. Water Research, v. 76, p. 187-200, 2015. https://doi.org/10.1016/j.watres.2015.02.059
SODRÉ, F. F.; LOCATELLI, M. A. F.; JARDIM, W. F. Occurrence of emerging contaminants in Brazilian drinking waters: A sewage-to-tap issue. Water, Air. and Soil Pollution, v. 206, p. 57-67, 2010. https://doi.org/10.1007/s11270-009 0086-9

SOUZA, B. P. DE. Avaliação da remoção de sulfametoxazol, diclofenaco e 17ß-estradiol em água por meio de processo oxidativo com cloro. Dissertação (Mestrado em Engenharia Civil) - Universidade Estadual Paulista, Ilha Solteira, 2014

STUMPF, M.; TERNES, T. A.; WILKEN, R. D.; RODRIGUES, S. V.; BAUMANN W. Polar drug residues in sewage and natural waters in the state of Rio de Janeiro, Brazil. Science of the Total Environment, v. 225, n. 1-2, p. 13-141, 1999 https://doi.org/10.1016/s0048-9697(98)00339-8

VALCÁRCEL, Y.; ALONSO, S. G.; RODRÍGUEZ-GIL, J. L.; GIL, M.; CATALÁ, $M$. Detection of pharmaceutically active compounds in the rivers and tap water of the Madrid Region (Spain) and potential ecotoxicological risk. Chemosphere, v. 84, n. 10, p. 1.336-1.348, 2011. https://doi.org/10.1016/j. chemosphere.2011.05.014

VERAS, T. B.; PAIVA, A. L. R.; DUARTE, M. M. M. B.; NAPOLEÃO, D. C.; CABRAL, J. J. S. P. Analysis of the presence of anti-inflammatories drugs in surface water: a case study in beberibe river - PE, Brazil. Chemosphere, v. 222, p. 961-969, 2019. https://doi.org/10.1016/j.chemosphere.2019.01.167

VULLIET, E.; CREN-OLIVÉ, C. Screening of pharmaceuticals and hormones at the regional scale, in surface and groundwaters intended to human consumption. Environmental Pollution, v. 159, p. 2.929-2.934, 2011. https:// doi.org/10.1016/j.envpol.2011.04.033 